\title{
Análise comparativa do isolamento acústico em diferentes geometrias: ensaios em campo e simulações computacionais
}

\author{
Comparative analysis of acoustic insulation in different \\ building geometries: field tests and computer simulations
}

\begin{abstract}
Maria Fernanda Oliveira Rafael Heissler

$\stackrel{\text { neaumo }}{\mathbf{n}}$

tualmente, no Brasil, as edificações residenciais devem atender condições mínimas de isolamento acústico, e, para tal, as características acústicas do sistema construtivo devem ser bem conhecidas. Para as condições de projeto, utilizam-se dados de isolamento acústico dos sistemas ensaiados em laboratório como valores de input em simulações computacionais, e assim estimar os resultados que poderão ser obtidos em ensaios em campo. Desse modo, este trabalho busca apresentar resultados de ruído aéreo e de impacto padronizado de diferentes sistemas construtivos ensaiados em uma mesma edificação, com foco na análise comparativa das diferentes áreas e geometrias e na estimativa obtida de softwares de predição acústica. Os ensaios foram realizados em edificações residenciais de acordo com as normas técnicas ISO 16283-1 e ISO 16283-2, e estimados com o uso do software SONarchitect. Uma análise da incerteza de medição a partir de uma série histórica de dados foi realizada para verificar se há influência da geometria na incerteza expandida. Verificou-se que parte dos ensaios de ruído aéreo apresentou resultados simulados com valor menor que os encontrados por meio de ensaio, e a incerteza de medição tende a um valor maior conforme o aumento do volume do cômodo ensaiado. Já para os ensaios de transmissão ao ruído de impacto, os valores estimados ficaram muito próximos dos resultados de ensaio, entretanto não foi possível relacionar a incerteza de medição com o volume do cômodo ensaiado.

Palavras-chave: Acústica de edifícios. Desempenho de edificações. Incerteza de medição.

\section{Abstract}

Currently in Brazil, residential buildings must be comply with basic acoustic insulation conditions, and in order to do that, the acoustic characteristics of the building system must be well known. For the design conditions, acoustic insulation data from laboratory tested systems are used as input values in computer simulations, thus estimating the results that can be obtained in field tests. This paper presents the results of air noise and standardised impact of different building systems tested in the same building, focusing on the comparative analysis of different areas and geometries and the estimation obtained from an acoustic prediction software. The tests were performed in residential buildings according to the technical standards ISO 16283-1 and ISO 16283-2 and estimated using the SONarchitect software. An analysis of measurement uncertainty from a historical data series was performed to verify whether geometry influences expanded uncertainty. It was verified that part of the air noise tests presented simulated results with smaller values than those found through the test, and measurement uncertainty tended to a higher value as the room volume increased. For the impact noise transmission tests, the estimated values were very close to the test results, however, it was not possible to relate the measurement uncertainty to the tested room volume.

Keywords: Building acoustics. Dwelling performance. Measurement uncertainty.
\end{abstract}




\section{Introdução}

A estimativa de resultados em acústica de edifícios é um tema que requer constante atualização, e a utilização de normas técnicas, como o conjunto das ISO 12354 (INTERNATIONAL..., 2017a., 2017b), é necessária para a avaliação de desempenho de sistemas construtivos na etapa de projeto (BURATTI; BELLONI; MORETTI, 2014; BUTKUS; JANUSEVICIUS; MAZUOLIS, 2011; DIKAVI et al., 2014). Os softwares se mostram ferramentas importantes para auxiliar nos cálculos, tanto pelos métodos de predição (FERREIRA; ZANNIN, 2007; PEÑA; COLINA; MORENO, 2002), quanto por métodos de análise por elementos finitos (OLIVEIRA; PATRICIO, 2017; POBLET-PUIG; GUIGOU-CARTER, 2015).

Atualmente, a NBR 15575-1 (ABNT, 2013a) não apresenta um critério para a escolha do sistema construtivo de partição e quais cômodos se deve utilizar como amostra para a determinação do desempenho acústico de edificações brasileiras. Nos casos de ensaios em campo em empreendimentos com unidades habitacionais diferentes entre si, somente um sistema construtivo pode ser avaliado para fins de comprovação para o agente do Sistema Financeiro Habitacional. Sabe-se que essa norma apresenta, por exemplo, requisito de isolamento acústico para divisórias de dormitórios de $45 \mathrm{~dB}$, mas uma edificação multifamiliar pode apresentar diversas configurações de paredes que se enquadrariam nesse caso. Além disso, sabe-se que em algumas situações existem diferentes geometrias a serem consideradas como amostras.

O isolamento acústico de elementos construtivos isoladamente é determinado em ensaios em laboratório. As câmaras reverberantes utilizadas para o ensaio devem estar totalmente desvinculadas de outros elementos construtivos, inclusive da amostra a ser ensaiada (HOPKINS, 2012). Quando realizados ensaios em campo, todos os elementos estão vinculados entre si e criam meios de transmissão da vibração pelos flancos, ou seja, pela via estrutural, no contato entre diferentes elementos e sistemas construtivos.

São quatro mecanismos principais que terão influência no controle da transmissão do ruído em elementos construtivos:
(a) a rigidez;
(b) a ressonância;
(c) a massa; e
(d) a coincidência.

Esses mecanismos corroboram a necessidade de se entender o espectro do som que se queira atenuar (GERGES; PAIXÃO, 2007). O isolamento acústico ao ruído aéreo depende da inércia, da massa e das características elásticas dos elementos utilizados na compartimentação de ambientes (HASSAN, 2009; PATRÍCIO, 2018). Além disso, o isolamento acústico de sistemas planos homogêneos varia em função da frequência, e o comportamento pode ser dividido em quatro regiões distintas (GERGES; PAIXÃO, 2007; LUNDH, 2017).

Para baixas frequências, a perda de transmissão sonora é controlada pela rigidez do material (LUNDH, 2017). Segundo Hopkins (2012), é muito difícil prever o comportamento do isolamento nas baixas frequências, mas esse é considerado um importante dado a ser verificado em sistemas de fachadas por causa da predominante componente espectral do ruído de tráfego nos sons graves, sendo essa a fonte sonora usualmente predominante nos estudos de isolamento sonoro de fachadas. Complementarmente, há a influência do controle das ressonâncias mecânicas de um sistema construtivo plano no movimento de flexão, que são o resultado da combinação construtiva de ondas de flexão que se propagam ao longo do painel e são irradiadas por suas bordas (BISTAFA, 2018).

O isolamento acústico também pode ser controlado pela massa do sistema construtivo em determinada faixa de frequências pela chamada "lei da massa". Nessa faixa, o isolamento tende a crescer $6 \mathrm{~dB}$ por acréscimo de banda de oitava (ANJOS, 2013; HOPKINS, 2012). A "lei da massa" é válida até a frequência de ressonância do sistema construtivo, denominada de "frequência crítica", quando a projeção do comprimento de onda incidente (onda plana) é igual ao comprimento de onda livre à flexão ao longo da parede, e a velocidade de propagação da onda incidente se iguala à velocidade de propagação da onda de flexão (GARCIA; VECCI; RODRIGUES, 2008). Esse efeito de coincidência faz a parede entrar em ressonância, transmitindo, então, a maior parte do som para a outra sala, o que compromete a privacidade sonora de ambientes internos.

Em sistemas verticais de alvenaria de blocos, a adição de revestimento em argamassa representa ganhos no isolamento acústico. No entanto, existe uma variação no ganho de isolamento proporcionado pelo uso do 
reboco em função da geometria dos blocos. De modo geral, os revestimentos em argamassa são mais eficientes para o aumento do isolamento acústico em alvenarias compostas de blocos com maior quantidade de vazados, representando um aumento de aproximadamente $1 \mathrm{~dB}$ para cada $1,0 \mathrm{~cm}$ de revestimento (KLIPPEL FILHO et al., 2019).

Quando se trata de isolamento ao ruído de impacto, atenção especial deve ser dada ao se determinarem os materiais construtivos a serem empregados. Esse tipo de transmissão é decorrente do impacto mecânico entre sólidos nos sistemas de piso, que, por sua característica intrínseca, sempre terá um ou mais elementos estruturais em sua composição. A estrutura de uma edificação, quando apresenta ligações rígidas e solidarizadas, é um meio suscetível a permitir a transmissão da vibração quando gerada por uma fonte de impacto, com pouca perda de energia (HOPKINS, 2012; PATRÍCIO, 2018).

A utilização de materiais com função de amortecimento a impactos mecânicos em sistemas de pisos pode ser uma solução para a redução da transmissão do som de impacto. O isolamento dos sons de impacto também varia em função da frequência, e a diferença entre sistemas de pisos com camadas rígidas e elásticas é verificada a partir da banda de $500 \mathrm{~Hz}$. Nesse ponto, é observado decaimento mais acentuado da força de excitação, quando na situação de utilização de revestimentos elásticos, como, por exemplo, pisos flutuantes e revestimentos macios (SIQUEIRA et al., 2018; ZINI et al., 2016; ZUCHETTO; NUNES; PATRÍCIO, 2016).

A redução sonora ao ruído aéreo de sistemas construtivos compostos pode ser largamente estimada, entretanto, ao se tratar de sistemas heterogêneos de pisos, a predição pode não ser tão simples assim (SCHOENWALD; GERRETSEN; MARTIN, 2008). Em alguns sistemas de piso são utilizados diferentes materiais de forma combinada, muitos deles leves e sem finalidade estrutural. De acordo com Hopkins (2012), lajes compostas por elementos leves não têm o mesmo comportamento acústico que uma laje maciça, que apresenta características de material heterogêneo e ortotrópico. Segundo Patrício (2018), nesse tipo de sistema construtivo são verificadas diferenças significativas nos mecanismos de transmissão pelos flancos, comparado à laje de concreto maciço homogênea, para uma densidade superficial similar. Ainda segundo o autor, a transmissão por flancos é um dos principais fatores que limitam o isolamento acústico nos sistemas de piso heterogêneos, mas com a utilização de acabamentos entre os flancos e a parede de alvenaria, acima e abaixo da laje, é possível melhorar consideravelmente seu desempenho. Essas características tornam as estimativas teóricas complexas devido aos diferentes tipos de ondas geradas nos diferentes materiais.

A caracterização teórica do isolamento acústico de sistemas construtivos pode ser realizada por diferentes métodos, como o elastodinâmico, de análise modal, de análise por elementos finitos e de análise estatística de energia (PATRÍCIO, 2018). Para Patrício (2018), o método elastodinâmico apresenta o fundamento básico dos demais e parte da formulação conceitual de um modelo inercial, que integra os efeitos de rigidez e de amortecimento interno. Dessa forma, a transmissão sonora é estimada com base no processo de deformação correspondente às diferentes características elásticas dos materiais e às consequentes interações do sistema construtivo a ser analisado. A consideração básica é fundamentada em uma placa plana, com espessura constante e desvinculada de seu contorno.

O método da matriz de transferência utiliza várias equações numéricas combinadas a parâmetros geométricos, resultando em gráficos que descrevem o comportamento acústico diante de uma excitação sonora. Esse modelo tem como vantagem poder variar as características e as configurações de um elemento multicamadas a ser modelado, assumindo que as camadas são infinitas, e representa uma propagação plana nas camadas (DIJCKMANSA; VERMEIR, 2013).

As normas para estimativas de isolamento acústico apresentam dois métodos de cálculo, sendo o método simplificado para a obtenção de resultado ponderado e o método detalhado para resultados por bandas de terço de oitava (INTERNATIONAL..., 2017a, 2017b). As comparações entre resultados de estimativas teóricas e por métodos experimentais podem ser realizadas com a finalidade de validar, ou não, dados de sistemas construtivos compostos por materiais de difícil caracterização. Essas validações são complexas, visto que os ensaios de acústica de edifícios podem apresentar variação entre medições repetidas. Diversos estudos nessa área testaram os limites de repetitividade, atestando que há variação entre repetidas medições (HEISSLER et al., 2016, 2017; MICHALSKI, 2011; WITTSTOCK, 2005; WSZOLEK, 2007).

Todos os modelos e métodos de estimativas partem da consideração da execução e da instalação corretas de elementos e sistemas construtivos, e erros de execução e de projeto podem não somente comprometer a eficiência do isolamento acústico, como também tornar inútil qualquer tentativa de cálculo (LABRES et al., 2018). 
Nesse contexto, deve-se salientar que qualquer expressão de resultados contém alguma dúvida, ou incerteza, em relação a valores quantitativos. A atual referência normativa para a incerteza de medição para acústica de edificações é a ISO 12999-1 (INTERNATIONAL..., 2014a) que fornece valores-referência para a incerteza padrão, devendo ser utilizados quando o laboratório não possuir dados de ensaios de proficiência para validar o método. Para desenvolver essa norma, uma série histórica de valores de ensaios interlaboratoriais foi levantada e tratada estatisticamente. Os valores representam uma média dos valores obtidos de diferentes tipos de mensurandos, incluindo paredes de sistemas leves, divisórias, paredes de sistemas pesados e esquadrias (INTERNATIONAL..., 2014a).

Procedimentos internacionais já são conhecidos e muito estudados para determinação da incerteza de medição, como o GUM (Guide to the Expression of Uncertainty in Measurement). Para a acústica de edifícios, a ISO 12999-1 (INTERNATIONAL..., 2014a) é a referência no assunto, a qual apresenta valores padrão para resultados de ensaios, mas não há um regulamento de limite à incerteza, na forma de limitar a variação de resultados de laboratórios diferentes.

Este trabalho busca analisar comparativamente as diferenças em resultados de perda de transmissão sonora e de redução ao nível de pressão sonora de impacto padrão, e a incerteza de medição com as diferenças geométricas de edificações. Foram considerados resultados de ensaios em campo, estimativas computacionais, com as verificações de incerteza na obtenção desses resultados.

\section{Método}

Foram analisados comparativamente resultados de ensaios em campo e de simulações computacionais de dez sistemas construtivos em dois diferentes empreendimentos habitacionais.

\section{Edificações amostradas}

Nas Figuras 1 e 2 são apresentadas as plantas dos dois empreendimentos utilizados neste estudo, com a indicação dos sistemas construtivos analisados.

O sistema de vedação vertical localizado entre unidades habitacionais distintas, do Edifício 1, é composto por alvenaria de blocos cerâmicos de vedação de dimensões de 19x19x29 cm, com revestimento argamassado com $1 \mathrm{~cm}$ de espessura, e espessura total da parede de $21 \mathrm{~cm}$. Nas salas/cozinhas, a parede ainda é revestida com azulejo cerâmico assentado com argamassa colante.

O sistema de vedação vertical da divisa da unidade habitacional com área comum de trânsito eventual, como o corredor, é composto por alvenaria de bloco cerâmico de vedação de dimensões de 14x19x29 cm, com revestimento em argamassa de múltiplo uso com $1 \mathrm{~cm}$ de espessura em projeto.

Figura 1 - Planta do pavimento-tipo do Edifício 1, com identificação dos cômodos ensaiados e das amostras LP1, LP2, LP3, LP4, LP5 e LP6

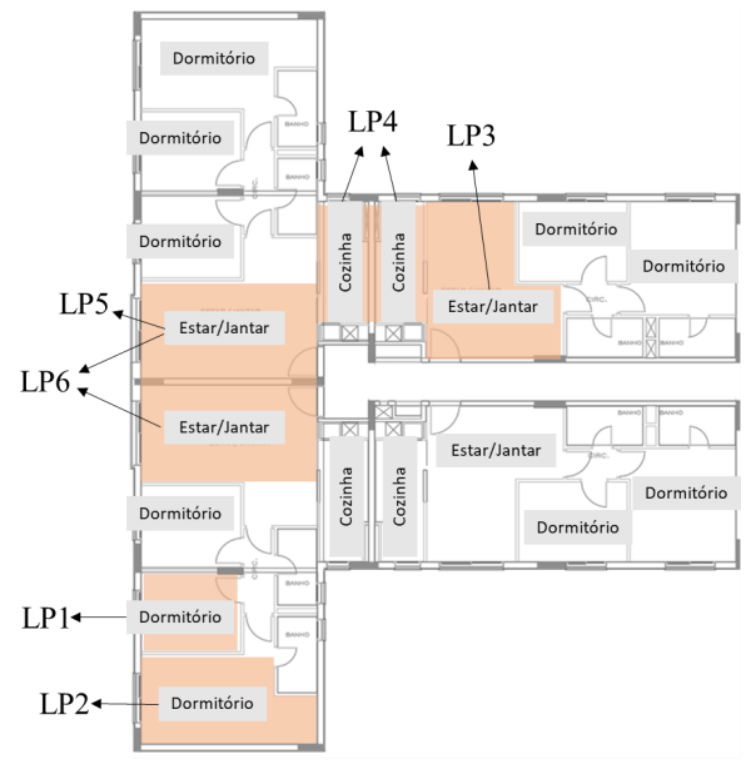


Figura 2 - Planta do pavimento-tipo do Edifício 2, com identificação dos cômodos ensaiados e das amostras NL1, NL2, NL3 e NL4

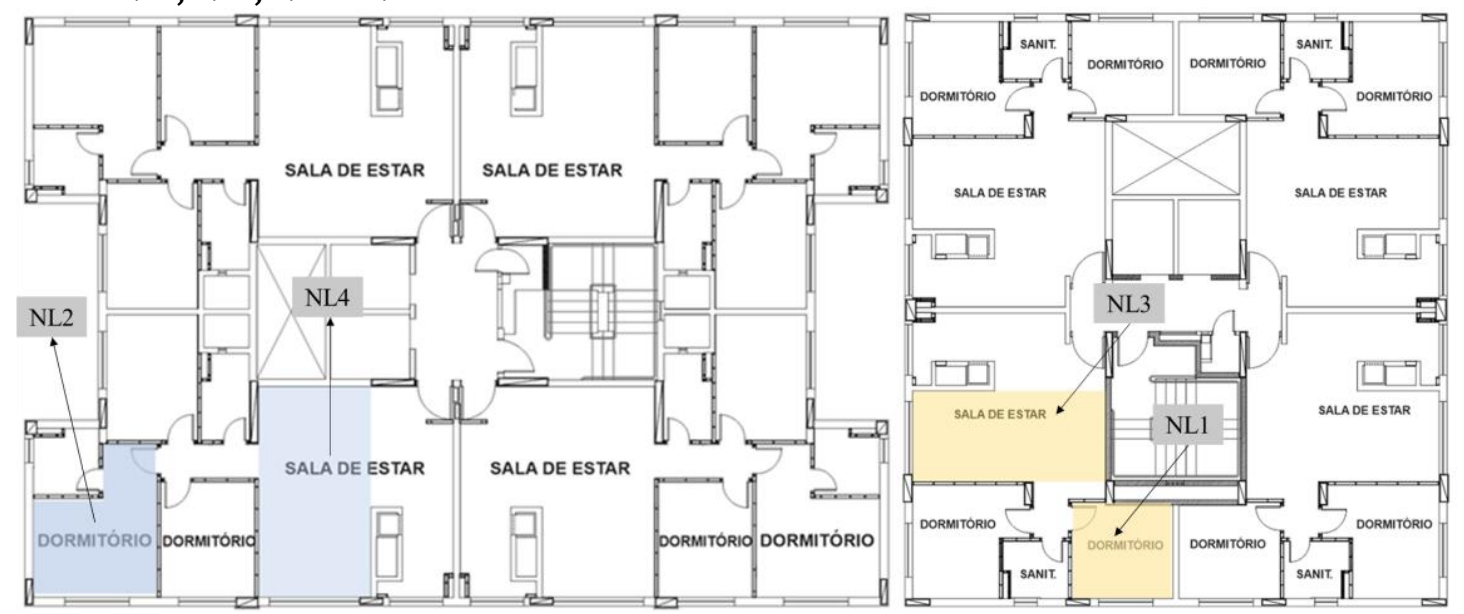

Já o Edifício 2 apresenta sistema de vedação vertical entre unidades habitacionais distintas, composto por alvenaria de blocos cerâmicos de vedação de dimensões de 14x19x29 cm com revestimento argamassado de $1 \mathrm{~cm}$. Nos dormitórios o sistema vertical de vedação é revestido com argamassa múltiplo uso com 1,3 cm de espessura em uma face e $2,2 \mathrm{~cm}$ de espessura na outra face, com espessura total da parede de $17,5 \mathrm{~cm}$. Nas salas/cozinhas, a parede é revestida com azulejo cerâmico Nórdico Snow Acetinado 29,6x40 cm, assentado com argamassa colante, com espessura de 2,2 cm em uma face e de 2,0 cm na outra face. Assim, as paredes das salas/cozinhas têm $18,2 \mathrm{~cm}$ de espessura total.

Para fins deste trabalho, os sistemas foram identificados conforme indicado na Tabela 1.

Os ambientes analisados têm ainda paredes externas de alvenaria de blocos cerâmicos de vedação de 19x19x29 cm, com revestimento argamassado de múltiplo uso com espessura média de 2,0 cm em ambas as faces, totalizando $23 \mathrm{~cm}$ de espessura.

As paredes internas das unidades habitacionais dos Edifícios 1 e 2 são de drywall, compostos por guias e montantes de $75 \mathrm{~mm}$ de espessura, preenchidos com lã de vidro com $50 \mathrm{~mm}$ de espessura e densidade de 12 $\mathrm{kg} / \mathrm{m}^{3}$, com espessura total de $100 \mathrm{~mm}$. Entre dormitórios e banheiros a distância entre montantes é de 40 $\mathrm{cm}$, com fechamento de placas de gesso acartonado de 12,5 $\mathrm{mm}$ de espessura, do tipo standard em uma face, e resistente à umidade na outra face. Nos demais ambientes, a distância entre montantes é de $60 \mathrm{~cm}$, com fechamento de placa de gesso acartonado standard de $12,5 \mathrm{~mm}$ em ambas as faces.

A laje dos Edifícios 1 e 2 é de concreto maciço moldado in loco com $12 \mathrm{~cm}$ de espessura e sem contrapiso. $\mathrm{Na}$ cozinha há ainda piso cerâmico Alfenas Natural Fit 44,5x44,5 cm.

\section{Ensaios em campo}

Para este trabalho foi utilizado o método de engenharia para o ensaio de isolamento ao ruído aéreo, seguindo procedimentos das normas ISO 16283-1 (INTERNATIONAL..., 2014b) e ISO 16283-2 (INTERNATIONAL..., 2015) para os ensaios de isolamento ao ruído aéreo e transmissão ao ruído de impacto respectivamente.

Em ambos os métodos os valores são expressos em bandas de terço de oitavas, nas faixas de frequências de $100 \mathrm{~Hz}$ a $3.150 \mathrm{~Hz}$. Para a expressão do valor único, foi utilizada a ISO 717-1 (INTERNATIONAL..., 2013b) para os ensaios de isolamento ao ruído aéreo e a ISO 717-2 (INTERNATIONAL..., 2013a) para ensaio de transmissão ao ruído de impacto.

O tempo de reverberação foi medido para cada ensaio de acordo com a ISO 3382-2 (INTERNATIONAL..., 2008), conforme o método de engenharia com ruído interrompido.

Foi utilizado Microfone B\&K 4189 acoplado em um sonômetro B\&K 2270. A verificação da calibração foi feita com Calibrador B\&K 4231, e a intensidade sonora foi gerada no amplificador B\&K 2734-A, ligado à fonte omnidirecional B\&K 4294-L. 


\section{Estimativa de desempenho acústico}

Optou-se por utilizar o software SONarchitect, o qual utiliza o grupo de normas EN 12354 para a predição do isolamento acústico de sistemas construtivos em edifícios, utilizando como dados de entrada do software valores estimados de acordo com a ISO 12354 (INTERNATIONAL..., 2017a, 2017b) para elementos construtivos homogêneos, e valores estimados pelo método da matriz de transferência para materiais não homogêneos ou multicamadas. Os modelos utilizados no método da matriz de transferência foram processados diretamente pelo software.

Os sistemas de paredes são compostos por blocos cerâmicos com diferentes espessuras e argamassa cimentícia como revestimento. A Tabela 2 resume os materiais utilizados como dados de input do software.

Tabela 3 apresenta os valores estimados no software pelo método da matriz de transferência, que tem como retorno o índice de redução sonora $(\mathrm{Rw})$.

\section{Incerteza de medição e levantamento histórico}

Para a estimativa da incerteza de medição, este trabalho adotou o método de trabalho apresentado na ISO/IEC Guide 98-3 (INSTITUTO..., 2008).

Neste trabalho a análise histórica de incerteza de medição foi realizada para se ter conhecimento do comportamento de incertezas e os fatores que as influenciam, para que a população amostral tenha um valor significativo e linhas de tendências e regressões estimem para valores mais robustos.

Visando contribuir com uma base histórica de dados, ensaios de isolamento acústico em campo realizados a partir de 2016 pelo Instituto Tecnológico itt Performance, da Unisinos, foram considerados para este trabalho, sendo 34 ensaios de isolamento ao ruído aéreo e 20 ensaios de transmissão ao ruído de impacto padrão. Esses ensaios foram realizados conforme método de ensaio da ISO 16283-1 (INTERNATIONAL, 2014b) para ensaio de ruído aéreo e da ISO 16283-2 (INTERNATIONAL..., 2015) para ensaios de transmissão ao ruído de impacto.

Tabela 1 - Síntese dos ensaios realizados e da geometria dos cômodos

\begin{tabular}{|c|c|c|c|c|c|c|c|c|}
\hline \multirow[b]{2}{*}{ Cômodo } & \multirow[b]{2}{*}{ Ident. } & \multirow[b]{2}{*}{ Edifício } & \multirow{2}{*}{$\begin{array}{c}\text { Área } \\
\text { partição } \\
\left(\mathbf{m}^{2}\right)\end{array}$} & \multirow[b]{2}{*}{$\begin{array}{l}\text { Tipo de } \\
\text { partição }\end{array}$} & \multirow[b]{2}{*}{$\begin{array}{l}\text { Espessura da } \\
\text { partição (m) }\end{array}$} & \multirow[b]{2}{*}{$\begin{array}{c}\text { Volume } \\
\left(\mathbf{m}^{3}\right)\end{array}$} & \multicolumn{2}{|c|}{ Método } \\
\hline & & & & & & & $\begin{array}{l}\text { Ruído } \\
\text { aéreo }\end{array}$ & $\begin{array}{l}\text { Ruído de } \\
\text { impacto }\end{array}$ \\
\hline Dormitório & LP1 & 1 & 12,0 & Piso & 0,12 & 31,8 & $\bar{x}$ & $\mathrm{x}$ \\
\hline Dormitório & LP2 & 1 & 14,8 & Piso & 0,12 & 39,2 & $\mathrm{x}$ & $\mathrm{x}$ \\
\hline Sala de estar & LP3 & 1 & 17,3 & Piso & 0,12 & 45,4 & $\mathrm{x}$ & $\mathrm{x}$ \\
\hline Sala de estar & LP4 & 1 & 9,8 & Parede & 0,21 & 45,7 & $\mathrm{x}$ & \\
\hline Sala de estar & LP5 & 1 & 20,1 & Piso & 0,12 & 52,9 & $\mathrm{x}$ & $\mathrm{x}$ \\
\hline Sala de estar & LP6 & 1 & 14,3 & Parede & 0,21 & 53,2 & $\mathrm{x}$ & \\
\hline Dormitório & NL1 & 2 & 9,0 & Piso & 0,12 & 23,8 & $\mathrm{x}$ & $\mathrm{x}$ \\
\hline Dormitório & NL2 & 2 & 11,3 & Piso & 0,12 & 29,9 & $\mathrm{x}$ & $\mathrm{x}$ \\
\hline Sala de estar & NL3 & 2 & 25,6 & Piso & 0,12 & 67,8 & $\mathrm{x}$ & $\mathrm{x}$ \\
\hline Sala de estar & NL4 & 2 & 31,5 & Piso & 0,12 & 83,5 & $\mathrm{x}$ & $\mathrm{x}$ \\
\hline
\end{tabular}

Tabela 2 - Descrição das divisórias estimadas

\begin{tabular}{c|l|c|c}
\hline Amostra & \multicolumn{1}{|c|}{ Descrição da divisória } & Rw (dB) & Densidade superficial $\left(\mathbf{k g} / \mathbf{m}^{2}\right)$ \\
\hline 1 & $\begin{array}{l}\text { Bloco cerâmico 14x19x29 cm; reboco } \\
\text { argamassado de } 1 \mathrm{~cm} \text { em ambas as faces }\end{array}$ & 41 & 160 \\
\hline 2 & $\begin{array}{l}\text { Bloco cerâmico 19x19x29 cm; reboco } \\
\text { argamassado de } 1 \mathrm{~cm} \text { em ambas as faces }\end{array}$ & 44 & 190 \\
\hline 3 & $\begin{array}{l}\text { Bloco cerâmico 19x19x29 cm; reboco } \\
\text { argamassado de 1,5 cm em uma das faces e } \\
2 \text { cm na outra }\end{array}$ & 44 & 230 \\
\hline 4 & $\begin{array}{l}\text { Bloco cerâmico 19x19x29 cm; reboco } \\
\text { argamassado de 3 cm em ambas as faces }\end{array}$ & 44 & 260 \\
\hline 5 & $\begin{array}{l}\text { Gesso acartonado com 1 placa em cada face } \\
\text { e manta de lã de vidro e banda acústica }\end{array}$ & 39 & 23 \\
\hline
\end{tabular}


Tabela 3 - Valores por banda de terço de oitava estimados para sistema não homogêneo, em dB

\begin{tabular}{c|c|c|c|c|c|c|c|c|c|c|c|c|c|c|c|c}
\hline \multirow{2}{*}{ Amostra } & \multicolumn{10}{c}{ Frequência (Hz) } \\
\cline { 2 - 14 } & $\mathbf{1 0 0}$ & $\mathbf{1 2 5}$ & $\mathbf{1 6 0}$ & $\mathbf{2 0 0}$ & $\mathbf{2 5 0}$ & $\mathbf{3 1 5}$ & $\mathbf{4 0 0}$ & $\mathbf{5 0 0}$ & $\mathbf{6 3 0}$ & $\mathbf{8 0 0}$ & $\mathbf{1 . 0 0 0}$ & $\mathbf{1 . 2 5 0}$ & $\mathbf{1 . 6 0 0}$ & $\mathbf{2 . 0 0 0}$ & $\mathbf{2 . 5 0 0}$ & $\mathbf{3 . 1 5 0}$ \\
\hline 1 & 35,1 & 36,2 & 36,3 & 33,6 & 29,3 & 27,9 & 30,2 & 36 & 40 & 45,8 & 49,5 & 52,4 & 57 & 61,4 & 60,2 & 62,7 \\
2 & 36,2 & 35,8 & 31,4 & 29,9 & 28,8 & 33,7 & 36,6 & 41,2 & 41,2 & 48,6 & 54,3 & 58,2 & 62,6 & 62,3 & 70,8 & 72,4 \\
3 & 36,8 & 36,7 & 33 & 30,1 & 27,4 & 32,2 & 36,1 & 41,9 & 47,2 & 50,3 & 54,5 & 58,5 & 61,8 & 61,3 & 66 & 73,8 \\
4 & 38,6 & 38,8 & 36,6 & 29,9 & 29,7 & 30,2 & 35,9 & 42,2 & 44,8 & 48,7 & 55,1 & 59,2 & 62,5 & 68 & 72,2 & 74,4 \\
5 & 17 & 20,4 & 25,5 & 26,9 & 29,1 & 31,3 & 33,7 & 36,1 & 38,7 & 41,3 & 43,8 & 46,2 & 48,1 & 48,6 & 45,8 & 37,4 \\
\hline
\end{tabular}

\section{Resultados e discussões}

\section{Ruído aéreo}

A Figura 3 apresenta os valores obtidos nos ensaios em campo e nas estimativas por software.

Quando analisados somente os resultados ponderados (Figura 4), percebe-se que os valores obtidos através de métodos de estimativa apresentaram valores mais conservadores em sua grande maioria (como pode ser percebido nas amostras NL1, NL2, NL3, NL4, LP1, LP2, LP4 e LP6). Ou seja, a estimativa neste caso apresentou resultado com valor mais elevado do que quando ensaiado em campo.

Entretanto, quando analisadas as amostras LP3 e LP5, verifica-se que a inversa da lógica observada anteriormente é válida, na qual os resultados obtidos em ensaios em campo apresentaram resultado com valor elevado em relação aos estimados pelo software.

Considerando a diferença entre os valores ponderados obtidos pelo ensaio em campo e pela estimativa, o conjunto de amostras NL3 e LP6 e o conjunto de amostras NL1 e NL4 apresentaram 1 dB e 2 dB respectivamente, indicando que os valores ficaram muito próximos entre si.

As amostras LP5 e NL2 apresentaram diferença no valor ponderado de 3 dB e 4 dB respectivamente, já apontando para um desvio maior que a incerteza padrão apresentada pela ISO 12999-1 (INTERNATIONAL..., 2014), que é de $2 \mathrm{~dB}$.

As amostras LP2, LP3, LP4 e LP1 apresentaram diferença no valor ponderado entre os valores obtidos pelo ensaio em campo e pela estimativa, maiores que $5 \mathrm{~dB}$. Isso indica que, considerando o que a NBR 15575-4 (ABNT, 2013c) traz como requisito mínimo, intermediário e superior, essa diferença obtida nos diferentes métodos estudados alteraria a classificação do sistema construtivo, visto que a diferença entre os requisitos de norma é $5 \mathrm{~dB}$.

A utilização de valores ponderados facilita a classificação de um sistema construtivo ou a comparação de sistemas distintos. Contudo, para uma análise mais refinada, utilizam-se os valores obtidos por bandas de frequência, podendo ser evidenciado o comportamento do sistema quanto a sua rigidez ou à frequência de coincidência e possíveis frestas e fragilidades em ensaios em campo (Figura 3).

\section{Ruído de impacto}

Os resultados obtidos no ensaio de nível de pressão sonora de impacto padrão realizados em campo e a estimativa realizada com software para as mesmas unidades são apresentados na Figura 5, com a síntese dos resultados, por bandas de terço de oitava, bem como o valor ponderado (Figura 6).

Ao analisar somente os resultados ponderados, percebe-se que os valores obtidos através do método de estimativa novamente apresentaram valores menores, podendo isso ser evidenciado na maior parte das amostras. Algumas ainda apresentam o mesmo valor ponderado em ambas as situações, conforme as amostras NL2 e LP1 (Figura 6).

Verifica-se que os resultados obtidos com ensaios em campo (Figura 3a) não apresentam o mesmo perfil gráfico que os resultados simulados. Muito disso pode ser indicado pelo fato de que o sistema analisado se constitui em um material homogêneo com a presença de elementos complementares, como instalação e tomadas, o que pode facilitar a transmissão sonora através destes.

Nos resultados obtidos na simulação computacional, a hierarquia dos valores é mais evidente, e a relação com o volume dos cômodos pode ser interpretada de forma mais direta. Dessa forma, pode-se indicar que, quanto maior o cômodo, menor será seu resultado estimado por bandas de frequência, sendo esta a expressão direta do modelo teórico. 
Nas baixas frequências é possível verificar uma variação que se repete em todos os dados de ensaio, principalmente nas bandas de $160 \mathrm{~Hz}$ e $200 \mathrm{~Hz}$, caracterizada por pico de transmissão de ruído. Isso não é notado nos resultados de campo e pode indicar que os sistemas ensaiados tinham rigidez maior que os sistemas modelados.

Figura 3 - Comparativo dos resultados ensaiados (E) e simulados (S) para o som aéreo (a) ensaiados e (b) simulados

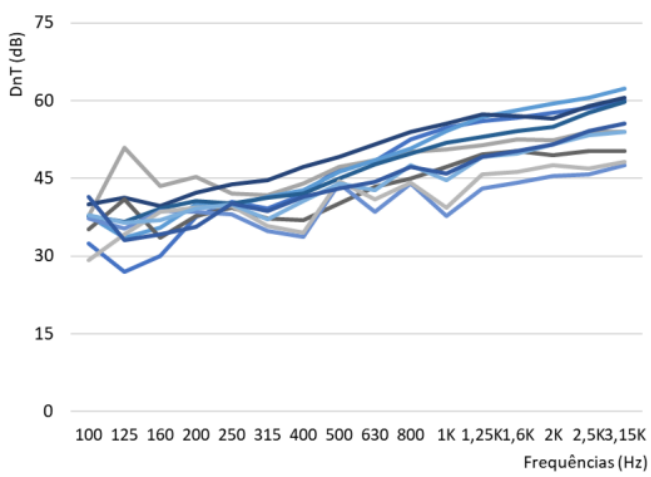

(a)

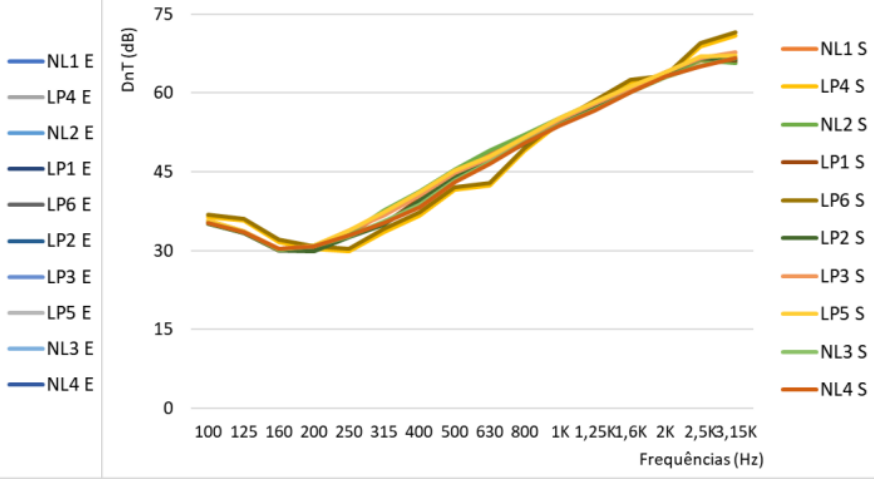

(b)

Figura 4 - Resultados ponderados ensaiados (E) e simulados (S) para o ruído aéreo

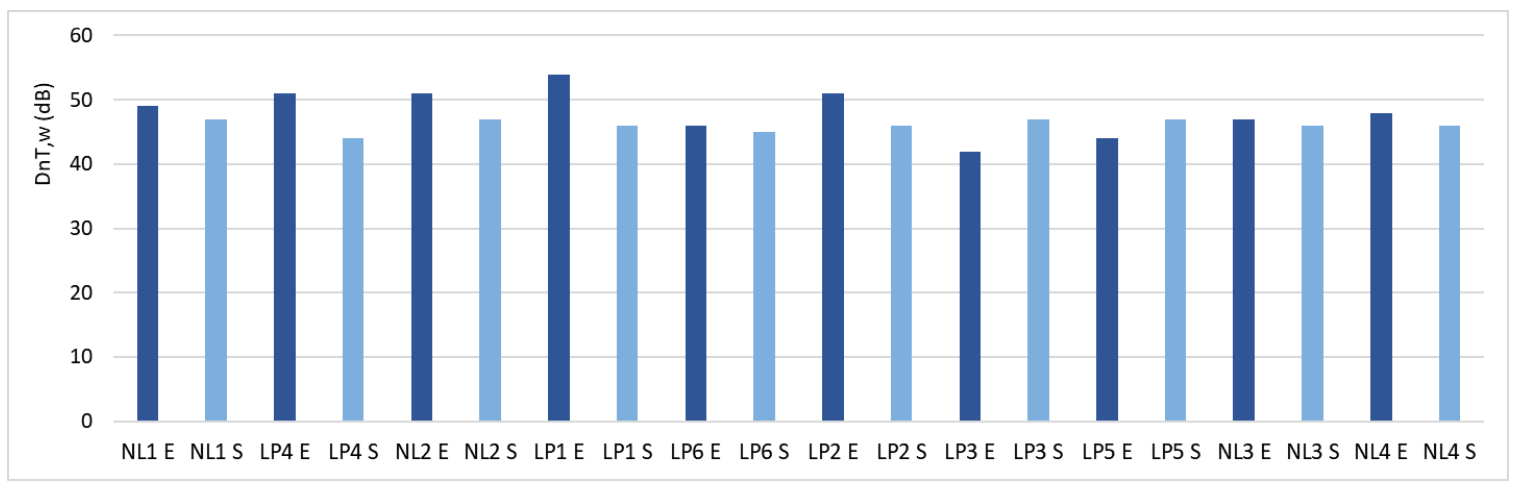

Figura 5 - Comparativo dos resultados ensaiados (E) e simulados (S) para o som de impacto (a) ensaiados e (b) simulados

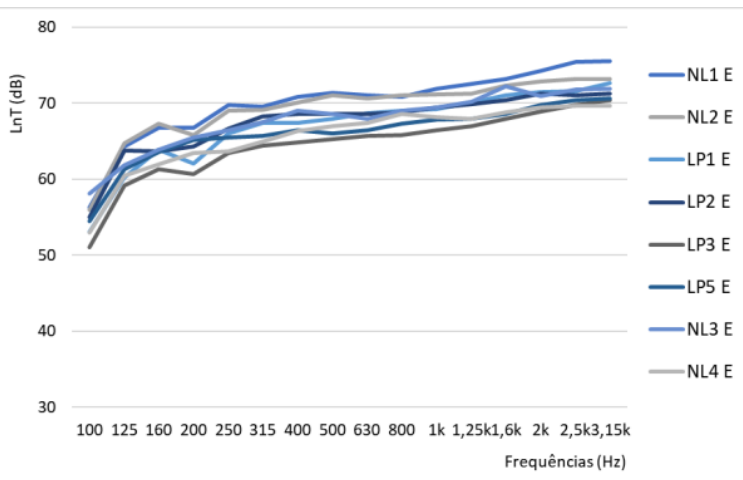

(a)

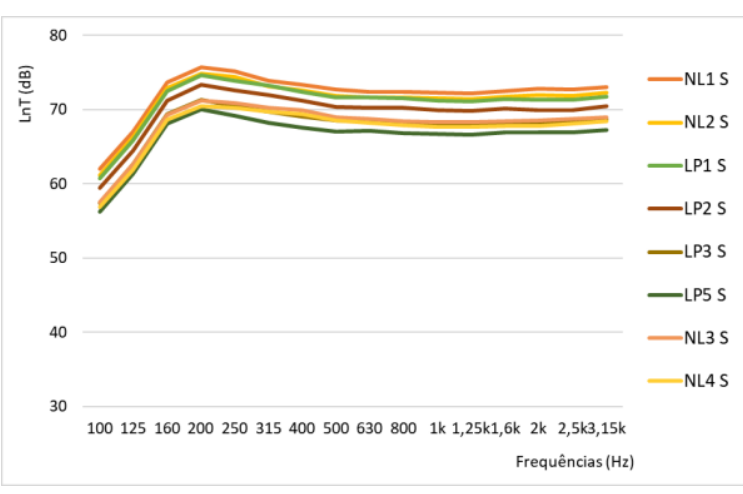

(b) 
Figura 6 - Resultados ponderados ensaiados (E) e simulados (S) para o ruído de impacto

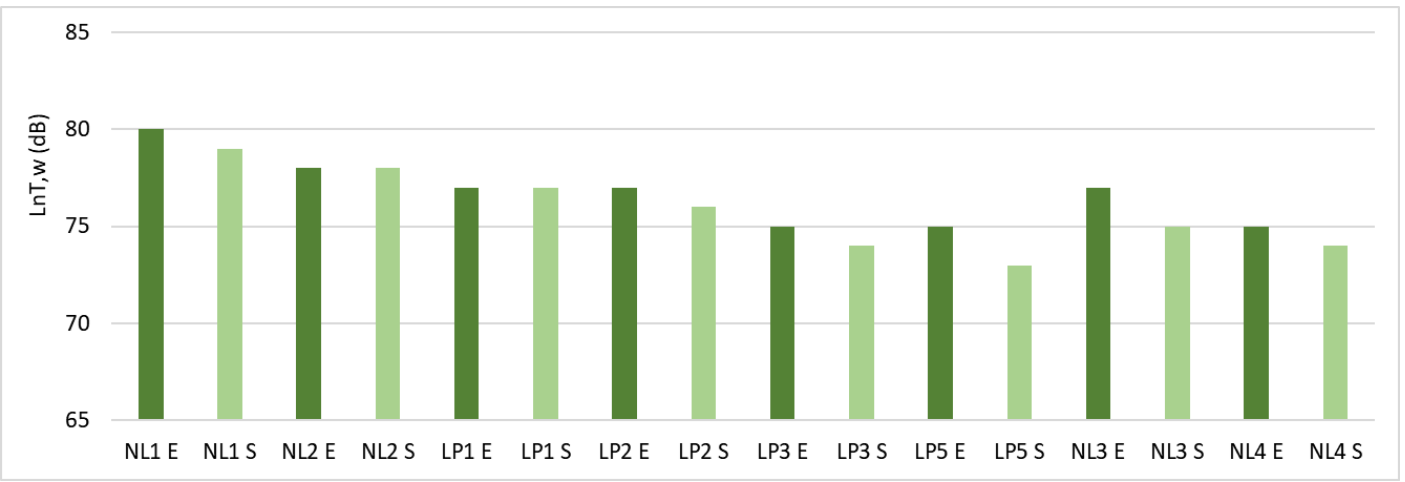

\section{Resultado do tempo de reverberação dos cômodos ensaiados}

O tempo de reverberação é utilizado como forma de correção dos valores para determinado ambiente ensaiado, tanto para a diferença de nível sonoro entre unidades, quanto para o nível de pressão sonora de impacto padrão. Conforme Hopkins (2012), quando o tempo de reverberação for corrigido para o valor de referência $\left(\mathrm{T}_{0}=0,5 \mathrm{~s}\right)$, o descritor acústico deverá se chamar "padronizado", e quando a área de absorção for corrigida para o valor de referência $\left(\mathrm{A}_{0}=10 \mathrm{~m}^{2}\right)$, o descritor acústico deverá se chamar "normalizado".

Neste trabalho, utilizaram-se os valores "padronizados", ou seja, corrigidos em função do tempo de reverberação do cômodo ensaiado, uma vez que são esses os descritores utilizados pela NBR 15575-2 (ABNT, 2013b). A Tabela 4 apresenta os valores do tempo de reverberação obtidos nos ensaios.

\section{Estimativa da incerteza de medição}

Para se obterem os valores de incerteza das medições, utilizou-se o método GUM para as estimativas de incerteza. Ressalta-se que esse procedimento se repete para todos os ensaios, tendo somente diferença no desvio padrão amostral obtido do processo de ensaio conforme a ISO 16283-1 (ABNT, 2014b) e a ISO 16283-2 (INTERNATIONAL..., 2015).

Buscando evidenciar todos os fatores que possam influenciar no resultado do processo de medição de um mensurando, utiliza-se diagrama de causa e efeito, também conhecido como diagrama de Ishikawa. A Figura 7 apresenta a proposta de diagrama contendo as causas de incertezas para o ensaio de ruído aéreo (Figura 7a) e ruído de impacto (Figura $7 b$ ).

Foram identificadas como causas as medições nos diferentes cômodos emissores e receptores (L1 e L2 respectivamente), sendo estes o desvio padrão amostral obtido das repetições realizadas em cada cômodo, a resolução utilizada e a incerteza de medição obtida da calibração do analisador sonoro, pré-amplificador e microfone - todas as causas com unidade em decibel.

Como causa na medição do tempo de reverberação, apresentado como $\mathrm{T}_{20}$, foram utilizadas as variáveis de medição, as quais são o desvio padrão do tempo de reverberação e a resolução do equipamento e do desvio padrão indicado pela ISO 3382-2 (INTERNATIONAL..., 2008), expresso com o símbolo $\sigma$. Todas as causas com unidade em segundo.

Verifica-se que na Figura 7 b não está representada a causa "L1" por não ser realizada essa medição no procedimento de ensaio de som de impacto.

A avaliação da incerteza padrão de um conjunto de medições, classificadas como do Tipo A, é definida pelo desvio padrão da média dos valores amostrados dividido pela raiz quadrada do tamanho da amostra.

A Equação 1 apresenta a incerteza padrão calculada do conjunto de dez medições realizadas no cômodo emissor (L1) na banda de frequência de $100 \mathrm{~Hz}$.

$u\left(L_{1}(100 \mathrm{~Hz})\right)=\frac{s\left(\overline{L_{1}}\right)}{\sqrt{n}}=\frac{3,9}{\sqrt{10}}=1,25 \mathrm{~dB}$

Eq. 1 
Tabela 4 - Valores do tempo de reverberação por banda de terço de oitava, em segundos

\begin{tabular}{c|c|c|c|c|c|c|c|c|c|c|c|c|c|c|c|c}
\hline $\begin{array}{c}\text { Amos- } \\
\text { tra }\end{array}$ & $\mathbf{1 0 0}$ & $\mathbf{1 2 5}$ & $\mathbf{1 6 0}$ & $\mathbf{2 0 0}$ & $\mathbf{2 5 0}$ & $\mathbf{3 1 5}$ & $\mathbf{4 0 0}$ & $\mathbf{5 0 0}$ & $\mathbf{6 3 0}$ & $\mathbf{8 0 0}$ & $\mathbf{1 . 0 0 0}$ & $\mathbf{1 . 2 5 0}$ & $\mathbf{1 . 6 0 0}$ & $\mathbf{2 . 0 0 0}$ & $\mathbf{2 . 5 0 0}$ & $\mathbf{3 . 1 5 0}$ \\
\hline LP1 & 0,76 & 1,04 & 1,04 & 1,84 & 2,16 & 2,61 & 2,81 & 2,80 & 2,74 & 2,79 & 2,60 & 2,33 & 2,12 & 1,89 & 1,69 & 1,54 \\
LP2 & 1,10 & 1,37 & 1,77 & 2,41 & 2,83 & 3,06 & 3,15 & 3,08 & 3,08 & 3,06 & 2,94 & 2,60 & 2,43 & 2,12 & 1,87 & 1,67 \\
LP3 & 1,27 & 1,49 & 1,53 & 2,04 & 2,07 & 2,49 & 2,52 & 2,97 & 3,15 & 3,08 & 2,86 & 2,59 & 2,29 & 1,95 & 1,74 & 1,71 \\
LP4 & 1,27 & 1,49 & 1,53 & 2,04 & 2,07 & 2,49 & 2,52 & 2,97 & 3,15 & 3,08 & 2,86 & 2,59 & 2,29 & 1,95 & 1,74 & 1,71 \\
LP5 & 1,70 & 2,71 & 1,84 & 2,24 & 2,52 & 2,77 & 2,94 & 3,25 & 3,42 & 3,24 & 3,33 & 3,15 & 2,78 & 2,44 & 2,23 & 2,11 \\
LP6 & 1,54 & 1,85 & 1,73 & 2,17 & 2,48 & 2,93 & 3,11 & 3,12 & 3,30 & 3,22 & 3,04 & 2,89 & 2,60 & 2,26 & 1,98 & 1,85 \\
NL1 & 0,91 & 1,09 & 1,50 & 2,04 & 2,14 & 2,57 & 2,92 & 2,87 & 2,78 & 2,63 & 2,47 & 2,23 & 2,02 & 1,79 & 1,52 & 1,38 \\
NL2 & 0,82 & 1,10 & 1,28 & 2,13 & 2,22 & 2,32 & 2,28 & 2,42 & 2,43 & 2,50 & 2,29 & 2,19 & 2,02 & 1,83 & 1,57 & 1,42 \\
NL3 & 1,34 & 1,79 & 1,90 & 2,09 & 2,46 & 2,28 & 2,46 & 2,75 & 2,57 & 2,69 & 2,51 & 2,40 & 2,18 & 2,07 & 1,88 & 1,74 \\
NL4 & 1,44 & 1,93 & 1,81 & 2,33 & 2,75 & 2,59 & 2,53 & 2,79 & 2,88 & 2,56 & 2,49 & 2,38 & 2,27 & 2,24 & 1,97 & 1,76 \\
\hline
\end{tabular}

Figura 7 - Diagrama de causa e efeito para ensaio de ruído aéreo (a) e ruído de impacto (b)

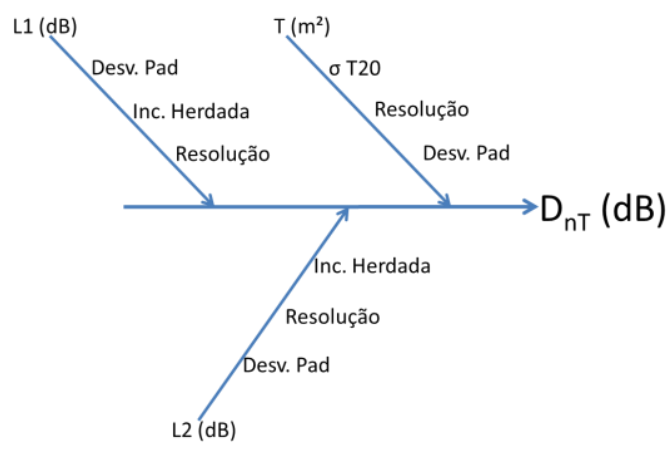

(a)

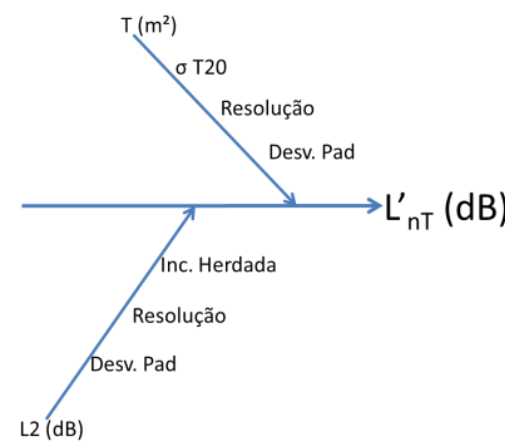

(b)

Para se obter o coeficiente de sensibilidade, é necessário calcular a derivada parcial de cada causa em relação ao efeito, utilizando como base o modelo matemático dos métodos de ensaio. Os coeficientes de sensibilidade encontrados estão apresentados na Tabela 5.

Conforme o proposto pela lei da propagação de incertezas, a incerteza combinada está apresentada na Equação 2 para o desvio padrão do tempo de reverberação para a banda de $100 \mathrm{~Hz}$ de frequência.

$u_{c}(y)=\sqrt{\sum_{i=1}^{N}\left(\frac{\partial y}{\partial x_{i}}\right)^{2} u^{2}\left(x_{i}\right)}=\sqrt{\sum_{i=1}^{N}\left(\frac{4,34}{1,53}\right)^{2} \times 0,176}=0,5$

Já a incerteza expandida é obtida através da multiplicação da incerteza combinada pelo fator de abrangência. A Tabela 6 apresenta a síntese dos dados utilizados para se determinar a incerteza de medição.

Por fim, a incerteza de medição no valor único deverá ser calculada. Para tal, utiliza-se o Anexo B da ISO 12999-1 (INTERNATIONAL..., 2014), o qual expõe um procedimento, visto que o valor único é uma unidade ponderada, apresentado na Tabela 7.

\section{Série histórica para ensaio de ruído aéreo}

Para melhor se verificar a dispersão dos valores de incerteza de medição por bandas de frequência, utilizouse do método estatístico denominado box plot, no qual os valores são fracionados em quartis, média e mediana. A Figura 8a apresenta o gráfico de box plot, com a média indicada com um ponto branco e a mediana como uma linha preta no interior da caixa. As caixas inferior e superior à linha da mediana condizem ao segundo e ao terceiro quadrante, e as linhas fora da caixa são o primeiro e o quarto quadrante. Os pontos vermelhos são valores outliers, que, para uma análise estatística com fator de abrangência maior, deverão ser desconsiderados. 
Tabela 5 - Coeficientes de sensibilidade

\begin{tabular}{|c|c|c|}
\hline $\begin{array}{l}\text { Estimativa } \\
\text { de entrada }\end{array}$ & Modelo matemático & $\begin{array}{c}\text { Coeficiente de } \\
\text { sensibilidade }\end{array}$ \\
\hline $\mathrm{L}_{1}$ & $\begin{array}{c}\text { Conforme a ISO 717-1 } \\
\text { (INTERNATIONAL..., 2013b) }\end{array}$ & $\frac{\partial D n t}{\partial L_{1}}=1$ \\
\hline $\mathrm{L}_{2}$ & $\begin{array}{c}\text { Conforme a ISO 717-1 } \\
\text { (INTERNATIONAL..., 2013b) }\end{array}$ & $\frac{\partial D n t}{\partial L_{2}}=-1$ \\
\hline $\mathrm{T}_{20}$ & $\begin{array}{c}\text { Conforme a ISO 717-1 } \\
\text { (INTERNATIONAL..., 2013b) }\end{array}$ & $\frac{\partial D n t}{\partial T_{20}}=\frac{4,34}{T_{20}}$ \\
\hline $\mathrm{L}_{2}$ & $\begin{array}{c}\text { Conforme a ISO 717-2 } \\
\text { (INTERNATIONAL..., 2013a) }\end{array}$ & $\frac{\partial L^{\prime} n t}{\partial L_{2}}=1$ \\
\hline $\mathrm{T}_{20}$ & $\begin{array}{c}\text { Conforme a ISO 717-2 } \\
\text { (INTERNATIONAL..., 2013a) }\end{array}$ & $\frac{\partial L^{\prime} n t}{\partial T_{20}}=\frac{4,34}{T_{20}}$ \\
\hline
\end{tabular}

Tabela 6 - Valores exemplificados por bandas de terço de oitava

\begin{tabular}{|c|c|c|c|c|c|c|c|c|c|c|c|c|c|c|c|c|}
\hline $\begin{array}{l}\text { Freq } \\
(\mathrm{Hz})\end{array}$ & 100 & 125 & 160 & 200 & 250 & 315 & 400 & 500 & 630 & 800 & 1.000 & 1.250 & 1.600 & 2.000 & 2.500 & 3.150 \\
\hline $\begin{array}{l}\text { D'nT } \\
\text { (dB) }\end{array}$ & 35,2 & 41,0 & 33,6 & 37,7 & 39,4 & 37,2 & 37,0 & 40,2 & 43,3 & 45,0 & 47,2 & 49,7 & 50,3 & 49,5 & 50,2 & 50,3 \\
\hline Veff & 20,9 & 21,9 & 16,2 & 21,2 & 18,0 & 16,5 & 20,7 & 23,0 & 23,9 & 17,0 & 30,9 & 38,3 & 63,8 & 42,7 & 53,4 & 44,2 \\
\hline $\mathrm{u}$ & 1,7 & 1,1 & 1,2 & 0,9 & 0,9 & 1,0 & 0,7 & 0,4 & 0,5 & 0,4 & 0,3 & 0,4 & 0,3 & 0,4 & 0,4 & 0,3 \\
\hline $\mathrm{k}$ & 2,1 & 2,1 & 2,2 & 2,1 & 2,1 & 2,2 & 2,1 & 2,1 & 2,1 & 2,2 & 2,1 & 2,1 & 2,0 & 2,1 & 2,0 & 2,1 \\
\hline$\pm \mathrm{U}(\mathrm{dB})$ & 3,7 & 2,4 & 2,7 & 1,8 & 1,9 & 2,1 & 1,4 & 0,9 & 1,0 & 0,9 & 0,6 & 0,8 & 0,7 & 0,8 & 0,7 & 0,7 \\
\hline
\end{tabular}

Tabela 7 - Síntese com valor único e incerteza de medição

\begin{tabular}{c|c|c|c|c}
\hline Amostra & Descritor & $\begin{array}{c}\text { Volume } \\
\left(\mathbf{m}^{3}\right)\end{array}$ & $\begin{array}{c}\text { Valor } \\
\text { ponderado (dB) }\end{array}$ & $\begin{array}{c}\text { Incerteza } \\
\text { expandida (dB) }\end{array}$ \\
\hline LP1 & L'nT,w & 32 & 77 & 1,0 \\
LP1 & DnT,w & 32 & 54 & 1,6 \\
LP2 & L'nT,w & 40 & 77 & 1,0 \\
LP2 & DnT,w & 40 & 51 & 1,7 \\
LP3 & L'nT,w & 45 & 75 & 1,0 \\
LP3 & DnT,w & 45 & 42 & 1,9 \\
LP4 & DnT,w & 46 & 52 & 1,9 \\
LP5 & L'nT,w & 53 & 75 & 1,4 \\
LP5 & DnT,w & 53 & 44 & 2,1 \\
LP6 & DnT,w & 53 & 46 & 1,7 \\
NL1 & L'nT,w & 24 & 80 & 0,9 \\
NL1 & DnT,w & 24 & 49 & 1,4 \\
NL2 & L'nT,w & 30 & 78 & 0,9 \\
NL2 & DnT,w & 30 & 47 & 1,7 \\
NL3 & L'nT,w & 68 & 77 & 1,7 \\
NL3 & DnT,w & 68 & 48 & 2,8 \\
NL4 & L'nT,w & 83 & 75 & 1,7 \\
NL4 & DnT,w & 83 & 51 & 1,4 \\
\hline
\end{tabular}

Como a população amostral deste trabalho é reduzida, boa parte dos valores outlier condiz com valores ensaiados em locais com volume maior, possivelmente pelo fato de não haver densidade amostral nesses valores. Realizando a análise da variância (Anova), os limites de desvio em cada banda são visualizados, conforme a Figura 8b.

A regressão linear apresentada na Figura $8 b$ retornou um desvio padrão global de $0,5 \mathrm{~dB}$, e o teste de normalidade de Anderson-Darling, o valor de 11,15 dB. Desse modo, a regressão linear não apresentou uma normalidade adequada em seus dados, e uma linha de tendência de regressão linear tenderá a apresentar um 
resíduo muito elevado. Assim sendo, utilizou-se uma linha de tendência em função polinomial de segunda ordem, apresentada na Figura 8c.

Esta linha de tendência apresentou um resíduo de 0,97 , ficando assim muito próximo de 1 . Conforme a linha de tendência proposta, a incerteza de medição na série histórica amostrada tende a dar os valores apresentados na Tabela 8 para o isolamento ao som aéreo.

Utilizando-se do método indicado anteriormente de média de variâncias, buscou-se um valor único de incerteza de medição em função do volume dos cômodos analisados. A Tabela 9 apresenta a síntese dos resultados encontrados de incerteza de medição média conforme o volume do cômodo amostrado.

Com esses dados foi verificada a dispersão dos valores com gráfico de box plot, apresentado na Figura 9a. Percebe-se que o limite inferior ficou em $1,3 \mathrm{~dB}$, o primeiro quartil em 1,6 dB, o terceiro quartil em $2,1 \mathrm{~dB}$, e o limite superior ficou em 2,8 dB. Já a média e a mediana ficaram com valores de 1,9 e 1,8 respectivamente. Neste caso, três valores foram enquadrados como outliers.

Considerando toda a população amostral, realizou-se a análise da variância desses valores em função do volume, podendo ser verificado na Figura 10. Essa análise representa de forma gráfica a influência dos valores outliers na regressão linear, com valores acentuados no volume de $37 \mathrm{~m}^{3}$ e de $87 \mathrm{~m}^{3}$. Desprezando-se os valores considerados outliers, condizentes com os valores mostrados nas Figuras 9a e 9b, a regressão linear de primeira ordem foi realizada, sendo apresentada na Figura 10. Verifica-se a dispersão dos resultados de incerteza mais clara, com a linha de tendência e uma relação com o volume dos cômodos ensaiados. Essa relação aponta que a incerteza média tende a ser maior quanto maior for o volume do cômodo ensaiado.

Figura 8 - Incerteza de medição do ruído aéreo: (a) box plot, (b) Anova e (c) linha de tendência de função polinomial de segunda ordem

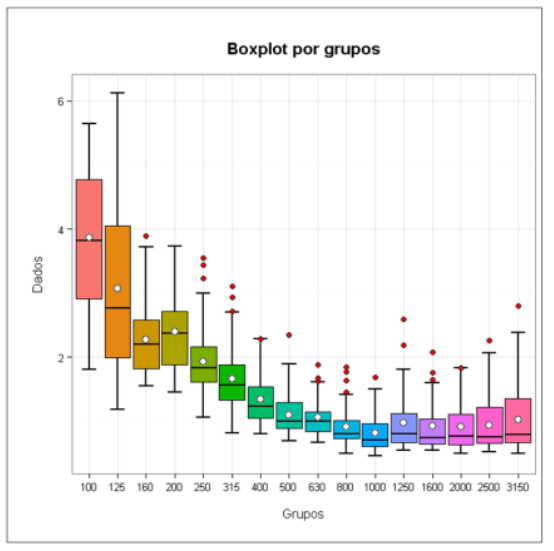

(a)

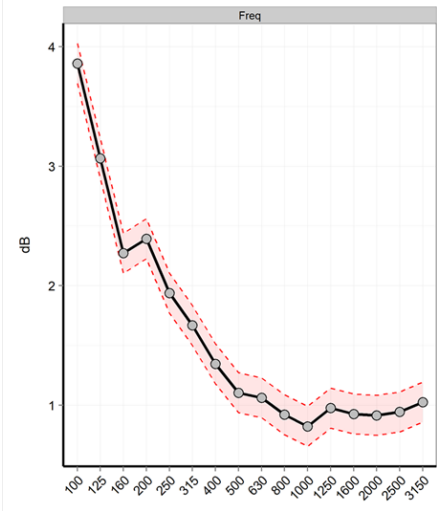

(b)

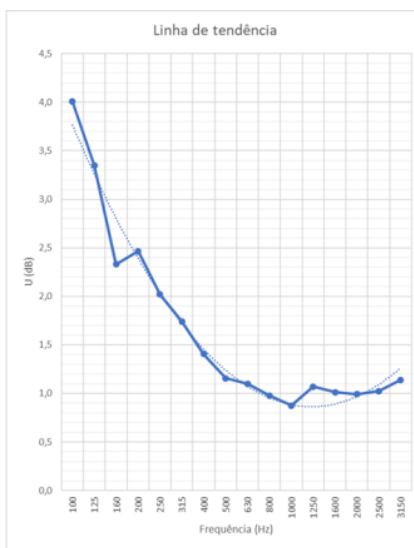

(c)

Tabela 8 - Tendência da incerteza de medição na série histórica amostrada para ruído aéreo

\begin{tabular}{c|c|c|c}
\hline $\begin{array}{c}\text { Frequência } \\
(\mathbf{H z})\end{array}$ & $\begin{array}{c}\mathbf{U} \\
(\mathbf{d B})\end{array}$ & $\begin{array}{c}\text { Frequência } \\
(\mathbf{H z})\end{array}$ & $\mathbf{U}(\mathbf{d B})$ \\
\hline 100 & 3,8 & 630 & 1,1 \\
125 & 3,3 & 800 & 1,0 \\
160 & 2,8 & 1.000 & 0,9 \\
200 & 2,4 & 1.250 & 0,9 \\
250 & 2,0 & 1.600 & 0,9 \\
315 & 1,7 & 2.000 & 1,0 \\
400 & 1,5 & 2.500 & 1,1 \\
500 & 1,2 & 3.150 & 1,3 \\
\hline
\end{tabular}


Tabela 9 - Incerteza média em função do volume do cômodo

\begin{tabular}{c|c|c|c|c|c}
\hline Volume $\left(\mathbf{m}^{3}\right)$ & $\mathbf{U}(\mathbf{d B})$ & Volume $\left(\mathbf{m}^{3}\right)$ & $\mathbf{U}(\mathbf{d B})$ & Volume $\left(\mathbf{m}^{3}\right)$ & $\mathbf{U}(\mathbf{d B})$ \\
\hline 24,0 & 1,9 & 36,0 & 1,5 & 64,0 & 2,2 \\
24,0 & 1,8 & 37,0 & 2,9 & 67,0 & 2,1 \\
24,0 & 1,7 & 37,0 & 2,9 & 67,0 & 1,7 \\
25,0 & 1,4 & 39,0 & 1,7 & 74,0 & 2,1 \\
25,0 & 1,6 & 40,0 & 1,7 & 75,0 & 2,1 \\
26,0 & 1,8 & 40,0 & 1,9 & 75,0 & 1,7 \\
27,0 & 1,3 & 43,0 & 1,7 & 76,0 & 1,7 \\
28,0 & 1,6 & 45,0 & 1,9 & 87,0 & 2,8 \\
30,0 & 1,6 & 52,0 & 2,1 & 110,0 & 1,4 \\
31,0 & 1,6 & 59,0 & 1,9 & 110,0 & 1,6 \\
31,0 & 1,4 & 61,0 & 2,1 & & \\
31,0 & 1,8 & 64,0 & 1,9 & & \\
\hline
\end{tabular}

Figura 9 - Incerteza de medição do ruído aéreo em função do volume

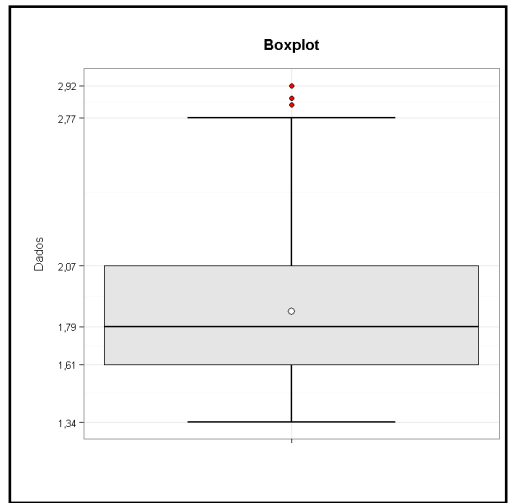

(a) Box plot

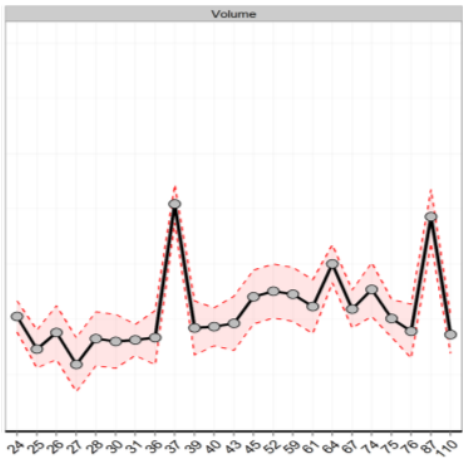

(b) Anova

Figura 10 - Linha de tendência de primeira ordem dos valores de incerteza de medição média em função do volume do cômodo

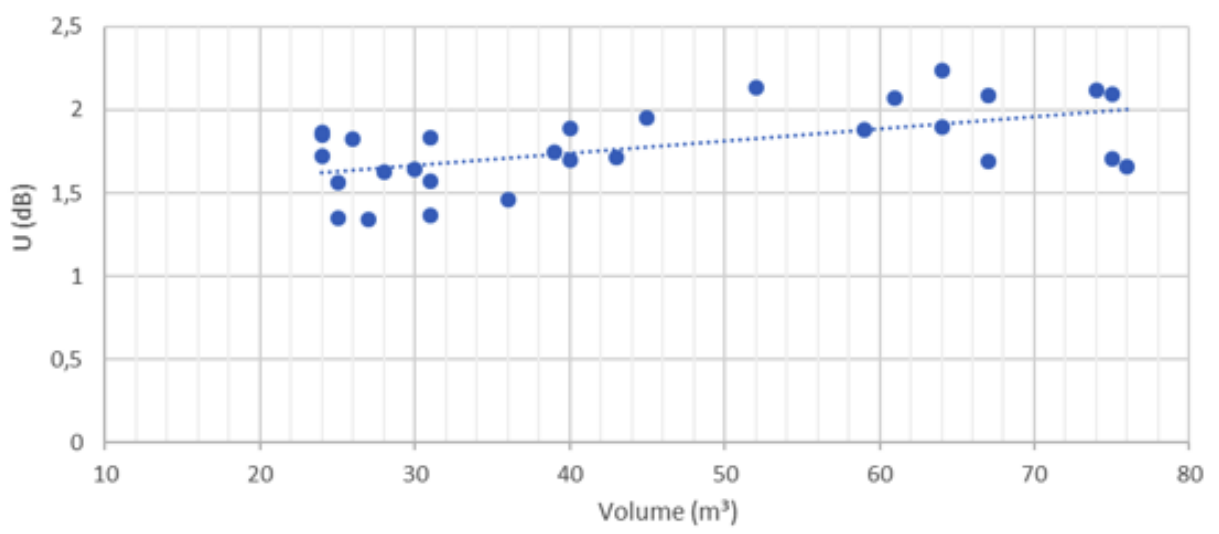

\section{Série histórica para ensaio de ruído de impacto}

A dispersão dos valores de incerteza de medição por bandas de frequência dos ensaios de ruído de impacto pode ser verificada na Figura 11a, que apresenta o gráfico de box plot, com valores fracionados em quartis, média e mediana. Quando realizado a Anova dos valores amostrados, os limites de desvio em cada banda são visualizados, conforme a Figura 11 b, enquanto a Figura 11c apresenta a linha de tendência obtida da média quadrada dos valores de incerteza por bandas de frequência. 
Percebe-se um comportamento que indica a incerteza mais elevada para as baixas frequências. Em médias frequências nota-se um leve decaimento, seguido de uma regularidade nos resultados, e em seguida um aumento nas altas frequências.

A linha de tendência de função polinomial de segunda ordem, apresentada na Figura 11c, apresentou um resíduo de 0,91. Conforme a linha de tendência proposta, a Tabela 10 apresenta os valores da incerteza de medição na série histórica.

Utilizando a média de variâncias, buscou-se um valor único de incerteza de medição em função do volume dos cômodos analisados. A Tabela 11 apresenta a síntese dos resultados encontrados de incerteza de medição média conforme o volume do cômodo amostrado.

Com esses dados foi verificada a dispersão dos valores com gráfico de box plot, apresentado na Figura 12a. Percebe-se que o limite inferior ficou em $0,7 \mathrm{~dB}$, o primeiro quartil em $0,9 \mathrm{~dB}$, o terceiro quartil em 1,6 dB, e o limite superior ficou em $2,8 \mathrm{~dB}$. Já a média e a mediana ficaram com valores de 1,3 e 1,1 respectivamente.

Nota-se maior dispersão da média de incertezas na Figura 12b. Para se verificar se esses dados são paramétricos, o teste de Cox-Stuart foi utilizado, indicando um p-valor de 1, ou seja, não há significância para um intervalo de confiança de $95 \%$. Logo, essa série temporal não é válida.

\section{Conclusão}

Este trabalho buscou analisar as possíveis diferenças entre resultados estimados e resultados de ensaios em campo de acústica de edificações de sistemas construtivos com diferenças geométricas em uma mesma edificação. No total, foram feitos dez ensaios para determinação da diferença padronizada de nível e oito ensaios para determinação do nível de pressão sonora de impacto padrão e a comparação com as respectivas estimativas pelo software SONarchitect.

Figura 11 - Incerteza de medição do ruído de impacto

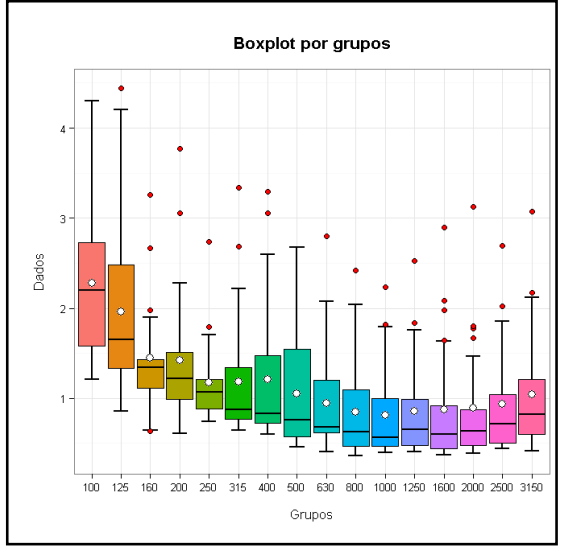

(a) Box plot

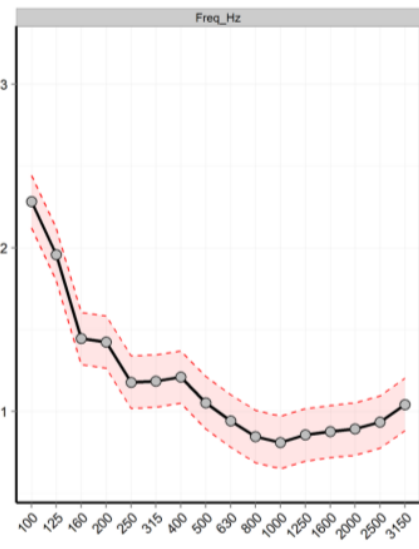

(b) Anova

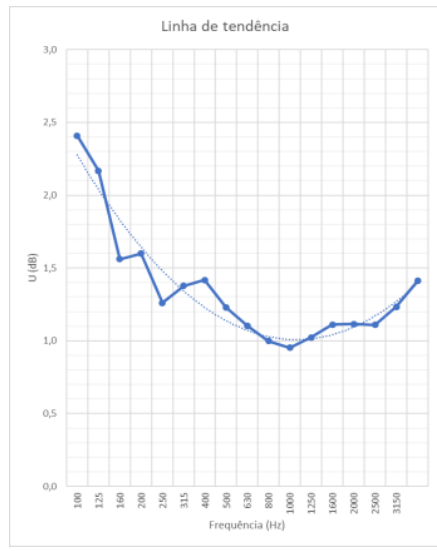

(c) Linha de tendência de função polinominal de segunda ordem

Tabela 10 - Tendência da incerteza de medição na série histórica amostrada para ruído de impacto

\begin{tabular}{c|c|c|c}
\hline Frequência $(\mathbf{H z})$ & $\mathbf{U}(\mathbf{d B})$ & Frequência $\mathbf{( H z )}$ & $\mathbf{U}(\mathbf{d B})$ \\
\hline 100 & 2,3 & 630 & 1,1 \\
125 & 2,0 & 800 & 1,0 \\
160 & 1,8 & 1.000 & 1,0 \\
200 & 1,6 & 1.250 & 1,0 \\
250 & 1,5 & 1.600 & 1,0 \\
315 & 1,3 & 2.000 & 1,1 \\
400 & 1,2 & 2.500 & 1,2 \\
500 & 1,1 & 3.150 & 1,3 \\
\hline
\end{tabular}

398 Oliveira, M. F.; Heissler, R. 
Tabela 11 - Incerteza média para ruído de impacto em função do volume do cômodo

\begin{tabular}{c|c|c|c}
\hline Volume $\left(\mathbf{m}^{\mathbf{3}}\right)$ & $\mathbf{U}(\mathbf{d B})$ & Volume $\left(\mathbf{m}^{\mathbf{3}}\right)$ & $\mathbf{U}(\mathbf{d B})$ \\
\hline 23 & 1,5 & 46 & 0,8 \\
24 & 0,9 & 52 & 1,2 \\
25 & 1,1 & 59 & 1,0 \\
27 & 3,1 & 61 & 2,1 \\
31 & 1,0 & 66 & 1,4 \\
31 & 0,9 & 70 & 1,7 \\
36 & 1,8 & 86 & 1,7 \\
38 & 1,0 & 91 & 0,8 \\
39 & 1,1 & 91 & 0,7 \\
42 & 1,1 & 110 & 0,9 \\
\hline
\end{tabular}

Figura 12 - Incerteza de medição do ruído de impacto em função do volume

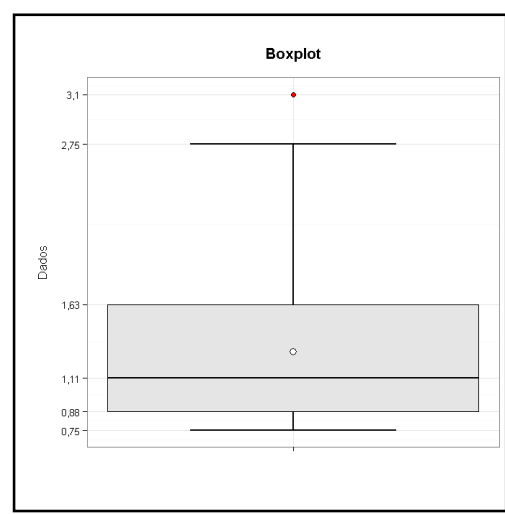

(a) Box plot

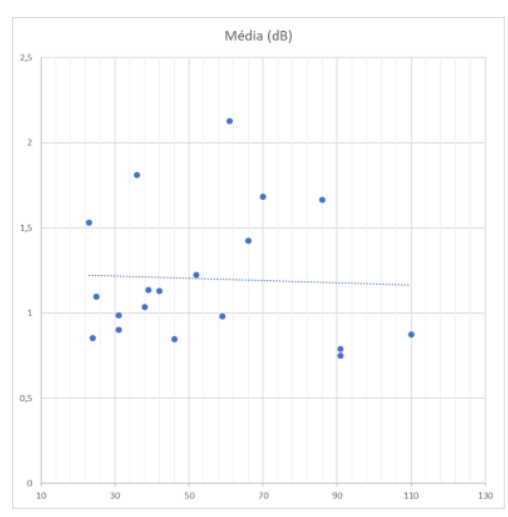

(b) Linha de tendência de primeira ordem

Ao se compararem os resultados ponderados de isolamento ao ruído aéreo com o volume dos cômodos receptores, não fica evidente uma tendência de resultado sendo influenciada por essa variável. Foram ensaiados e simulados sistemas construtivos em cômodos com diferentes volumes, entre 23,8 $\mathrm{m}^{3}$ (Amostra NL1) e 83,5 $\mathrm{m}^{3}$ (Amostra NL4), obtendo-se variações nos resultados ponderados entre $2 \mathrm{~dB}$ e $5 \mathrm{~dB}$, considerando-se os ensaios em campo e as simulações via software. Dessa forma, pode-se afirmar que a diferença entre os resultados ponderados de ensaios em campo e de estimativas via software pode chegar a 5 $\mathrm{dB}$.

Na relação entre o resultado ponderado do ruído de impacto obtido e o volume dos cômodos receptores, um padrão torna-se amostrado nos resultados até determinado volume. Considerando-se os valores obtidos em ensaios em campo para cômodos de até $45 \mathrm{~m}^{3}$, houve uma relação inversamente proporcional, sendo que, quando observado aumento no volume do cômodo amostrado, o resultado tendia a ser menor. Entretanto, nas demais amostras esse comportamento não foi observado.

A incerteza de medição se mostrou um parâmetro avaliativo da regularidade dos ensaios, e destaca-se que valores intrínsecos à geometria de unidades influenciam nos valores da incerteza expandida.

Conclui-se que as diferenças de volume dos cômodos são uma característica inerente das edificações a serem estudadas e que a variação desse dado ocasiona resultados desiguais. Foi possível verificar um padrão entre o volume do cômodo receptor e os resultados obtidos, e relações entre o volume do cômodo receptor e a incerteza de medição em uma série amostrada somente para o ruído de impacto. Considerando-se os resultados de ruído de impacto, houve uma relação de inversamente proporcional, sendo que, quanto maior o volume do cômodo, menor o resultado ponderado. Os resultados relativos à diferença padronizada de nível indicam que as incertezas aumentam com volumes maiores do cômodo receptor. 


\section{Referências}

ASSOCIAÇÃO BRASILEIRA DE NORMAS TÉCNICAS. NBR 15575-1: edificações habitacionais: desempenho: parte 1: requisitos gerais. Rio de Janeiro, 2013a.

ASSOCIAÇÃO BRASILEIRA DE NORMAS TÉCNICAS. NBR 15575-2: edificações habitacionais: desempenho: parte 3: requisitos para os sistemas de pisos. Rio de Janeiro, 2013b.

ASSOCIAÇÃO BRASILEIRA DE NORMAS TÉCNICAS. NBR 15575-4: edificações habitacionais: desempenho: parte 4: requisitos para os sistemas de vedações verticais internas e externas — SVVIE. Rio de Janeiro, 2013c.

ANJOS, M. A. R. Caracterização do conforto acústico em edifícios de habitação. Lisboa, 2013. 49 f. Dissertação (Mestrado em Engenharia Civil) - Faculdade de Ciências e Tecnologia, Universidade Nova de Lisboa, Lisboa, 2013.

BISTAFA, Sylvio R. Acústica aplicada ao controle do ruído. 3. ed. São Paulo: Blucher, 2018.

BURATTI, C.; BELLONI, E.; MORETTI, E. Façade noise abatement prediction: new spectrum adaptation terms measured in field in different road and railway traffic conditions. Applied Acoustics, v. 76, p. 238248, 2014.

BUTKUS, D.; JANUSEVICIUS, T.; MAZUOLIS, J. Building partitions acoustic properties. Environmental Engineering, v. 1, p. 43-79, 2011.

DIJCKMANSA, A.; VERMEIR, G. Development of a hybrid wave based-transfer matrix model for sound transmission analysis. Journal of the Acoustical Society of America, v. 133, n. 4, p. 2157-2168, 2013.

DIKAVI, V. et al. Relation between reduction of weighted impact sound pressure level and shape of small size specimen of floating floor construction. Journal of Vibroengineering, v. 16, n. 3, p. 1297-1305, 2014.

FERREIRA, J. A. C.; ZANNIN, P. H. T. Determinação de coeficientes de isolamento acústico: medições. Ambiente Construído, Porto Alegre, v. 7, n. 2, p. 15-29, abr./jun. 2007.

GARCIA, D. B.; VECCI, M. A. de E. M.; RODRIGUES, F. C. Avaliação do isolamento sonoro aéreo de elementos de vedação na construção civil. Ambiente Construído, Porto Alegre, v. 8, n. 1, p. 49-63, jan./mar. 2008.

GERGES, S. N. Y.; PAIXÃO, D. X. da. Influência de propriedades físico-mecânicas para a determinação da frequência de coincidência no isolamento sonoro de paredes de alvenaria. Ambiente Construído, Porto Alegre, v. 7, n. 3, p. 143-157, jul./set. 2007.

HASSAN, O. A. B. Building acoustics and vibration: theory and practice. London: World Scientific, 2009.

HEISSLER, R. F. et al. Análise crítica do desempenho acústico de sistemas de revestimentos de pisos. In: ENCONTRO NACIONAL DA SOCIEDADE BRASILEIRA DE ACÚSTICA, 27., Brasília, 2017. Anais [...] Brasília: Sobrac, 2017.

HEISSLER, R. F. et al. Uncertainty in measurement determination in the sound reduction index in laboratory. In: INTERNATIONAL CONGRESS ON ACOUSTICS, 22., Buenos Aires, 2016. Proceedings [...] Buenos Aires: ICA, 2016.

HOPKINS, C. Sound insulation. Burlington: Elsevier, 2012.

INSTITUTO NACIONAL DE METROLOGIA, QUALIDADE E TECNOLOGIA. Avaliação de dados de medição: guia para a expressão de incerteza de medição. JCGM 100, 2008.

INTERNATIONAL STANDARD ORGANIZATION, ISO 3382-2: acoustics: measurement of room acoustic parameters: part 2: reverberation time in ordinary rooms. Geneva, 2008.

INTERNATIONAL STANDARD ORGANIZATION. ISO 12354-1: building acoustics: estimation of acoustic performance of buildings from the performance of elements: part 1: airborne sound insulation between rooms. Genebra, 2017a.

INTERNATIONAL STANDARD ORGANIZATION. ISO 12354-2: building acoustics: estimation of acoustic performance of buildings from the performance of elements: part 2: impact sound insulation between rooms. Genebra, 2017b. 
INTERNATIONAL STANDARD ORGANIZATION. ISO 12999-1: acoustics: determination and application of measurement uncertainties in building acoustics: part 1: sound insulation. Genebra, 2014a

INTERNATIONAL STANDARD ORGANIZATION. ISO 16283-1: acoustics: field measurement of sound insulation in buildings and of building elements: part 1: airborne sound insulation. Genebra, 2014b.

INTERNATIONAL STANDARD ORGANIZATION. ISO 16283-2: acoustics: field measurement of sound insulation in buildings and of building elements: part 2: impact sound insulation. Genebra, 2015.

INTERNATIONAL STANDARD ORGANIZATION. ISO 717-1: acoustics: rating of sound insulationd in buildings elements: part 1: airborne sound insulation. Genebra, $2013 \mathrm{~b}$.

INTERNATIONAL STANDARD ORGANIZATION. ISO 717-2: acoustics: rating of sound insulation in buildings and of building elements: part 2: impact sound insulation. Genebra, 2013a.

KLIPPEL FILHO, S. et al. Influência da espessura de revestimentos de argamassa no desempenho acústico de alvenarias de blocos cerâmicos. Ambiente Construído, Porto Alegre, v. 19, n. 2, p. 145-156, abr./jun.2019.

LABRES, H. S. et al. Acoustic performance of brick masonry walls: construction defects and influence of installations. Building Acoustics, v. 25, n. 4, p. 351-362, 2018.

LUNDH, H. Sustainable thermal and acoustic retrofitting of façade walls. Lund: Lund University, Sweden, 2017.

MICHALSKI, R. L. X. N. Metodologias para medição de isolamento sonoro em campo e para expressão da incerteza de medição na avaliação do desempenho acústico de edificações. Rio de Janeiro, 2011. 235 f. Tese (Doutorado em Engenharia Mecânica) - Programa de Pós-Graduação em Engenharia Mecânica, Universidade Federal do Rio de Janeiro, Rio de Janeiro, 2011.

OLIVEIRA, M. F.; PATRICIO, J. V. Impact noise of non-homogeneous floors: analysis of different input parameters for computational modeling predictions. Journal of Civil Engineering and Architecture, v. 11, n. 3, p. 274-281, 2017.

PATRÍCIO, J. V. Acústica nos edifícios. 6. ed. Lisboa: Verlag Dashöfer, 2018.

PEÑA, M. A.; COLINA, C. de la; MORENO, A. IAPAI, Software to predict acoustic insulation in buildings in accordance with EN 12354/1/2. In: FORUM ACUSTICUM, 2002. Proceedings [...] Sevilla: Sociedade Espanhola de Acústica, 2002.

POBLET-PUIG, J.; GUIGOU-CARTER, C. Using spectral finite elements for parametric analysis of the vibration reduction index of heavy junctions oriented to flanking transmissions and EN-12354 prediction method. Applied Acoustics, v. 99, p. 8-23, 2015.

SCHOENWALD, S.; GERRETSEN, E.; MARTIN, H. J. Prediction of the sound transmission loss of multilayered small sized elements. The Journal of the Acoustical Society of America, v. 123, n. 5, p. 3500, 2008.

SIQUEIRA, A. P. L. et al. Análise do desempenho acústico de camadas elásticas de pisos flutuantes. In: ENCONTRO NACIONAL DA SOCIEDADE BRASILEIRA DE ACÚSTICA, 28., Porto Alegre, 2018. Anais [...] Porto Alegre: Sobrac, 2018.

WITTSTOCK, V. Uncertainties in building acoustics. In: FORUM ACUSTICUM 2005. Anais [...]. Budapest: European Acoustics Association, 2005.

WSZOLEK, T. Uncertainty of sound insulation measurement in laboratory. Archives of Acoustics, v. 4, p. 271-277, 2007.

ZINI, A. et al. Sound Insulation of floors: a new composite with a resilient layer of recycled polymer. Journal of Civil Engineering and Architecture, v. 10, n. 8, p. 861-869, 2016.

ZUCHETTO, L. K.; NUNES, M. F. O.; PATRÍCIO, J. V. The effect of addition of layers on impact sound insulation of floors. In: INTER-NOISE, 45., 2016. Anais [...] Hamburgo: Institute of Noise Control Engineering, 2016. 
Maria Fernanda de Oliveira

itt Performance | Universidade do Vale dos Sinos | Av. Unisinos, 950, Bairro Cristo Rei | São Leopoldo - RS - Brasil | CEP 93022-750 | Tel.: (51) 3590-8887 | E-mail: mariaon@unisinos.br

\section{Rafael Ferreira Heissler}

itt Performance | Universidade do Vale dos Sinos | E-mail: rheissler@unisinos.br

\section{Ambiente Construído}

Revista da Associação Nacional de Tecnologia do Ambiente Construído

Av. Osvaldo Aranha, $99-3^{\circ}$ andar, Centro

Porto Alegre - RS - Brasil

CEP 90035-190

Telefone: +55 (51) 3308-4084

Fax: +55 (51) 3308-4054

www.seer.ufrgs.br/ambienteconstruido

E-mail: ambienteconstruido@ufrgs.br 